\title{
A HISTÓRIA DA CIÊNCIA COMO “REMÉDIO” NO ENSINO DE QUÍMICA: EPISÓDIO - ESTUDO SOBRE A INVENÇÃO DA TEORIA ATÔMICO-MOLECULAR MODERNA
}

\author{
César de B. Lobato ${ }^{\mathrm{a}, *,(1)}$ \\ aDepartamento de Química, Instituto Federal de São Paulo, 08673-010 Suzano - SP, Brasil
}

Recebido em 18/01/2020; aceito em 10/06/2020; publicado na web em 21/07/2020

\begin{abstract}
THE HISTORY OF SCIENCE AS A "REMEDY" IN THE TEACHING OF CHEMISTRY: EPISODE - STUDY ON THE INVENTION OF MODERN ATOMIC-MOLECULAR THEORY. In recent years, much has been said about the approach of the history of science and science teaching. We know that this approach can be made using historical episodes in science classes. In this sense, this work aims to bring a historical episode to be worked on in general chemistry classes in high school, as well as in general chemistry classes 1 of university courses. Thus, we will first make some considerations about the importance of the history of science for teaching chemistry. Then, we will bring the episode that analyzes some of the works that formed the basis of modern chemical thought. From the historical episode we worked on, we intend to show the complex construction of modern atomic-molecular theory. However, it is important to emphasize that, for didactic purposes, we cut the debate, bringing up only the speeches of three of the main authors of the time. Special attention was paid to Dalton's work.
\end{abstract}

Keywords: Dalton; Gay-Lussac; Avogadro; History of Science; Chemistry teaching.

\section{INTRODUÇÃO}

Nos últimos anos, muito se tem falado sobre a aproximação da história da ciência e o ensino de ciências. Isso porque a história da ciência auxilia a compreensão e a ressignificação dos resultados científicos atualmente aceitos. Sabemos, a partir disso, que essa aproximação pode ser feita utilizando episódios históricos nas aulas de ciências. Nesse sentido, este trabalho tem como objetivo trazer um episódio histórico para ser trabalhado nas aulas de química geral no ensino médio, assim como, possivelmente, nas aulas de química geral 1 de cursos universitários.

Primeiramente faremos algumas considerações sobre a importância da história da ciência para o ensino de química. Depois, mostraremos o episódio que analisa alguns dos trabalhos que formaram a base do pensamento químico moderno. Nesse episódio, inicialmente, analisaremos a publicação de Dalton, em 1808, depois, nos debruçaremos no debate entre ele e Gay-Lussac. Também analisaremos a proposta de Avogadro, em 1811. Por último, faremos algumas considerações sobre a recepção das ideias atômicas no século XIX.

Por este ser um texto com pretensões didáticas, excluímos de nossas análises os trabalhos de outros importantes personagens dessa história. Estamos trazendo à tona apenas as falas de três dos principais autores da época, sendo que uma atenção especial foi dada ao trabalho de Dalton.

Portanto, pelo fato de nosso artigo ter como foco o processo de construção dos conceitos químicos, acreditamos que ele seja de fundamental importância para o processo de ensino-aprendizagem e, por consequência, para o ensino de química.

\section{CONSIDERAÇÕES SOBRE A IMPORTÂNCIA DA HISTÓRIA DA CIÊNCIA PARA O ENSINO DE QUÍMICA}

Em relação à aproximação da história da ciência e o ensino de ciências, temos três questões que consideramos relevantes. A primeira é: por que aproximar a história da ciência e o ensino de ciências?

\footnotetext{
*e-mail: cesar.lobato@ifsp.edu.br
}

Acreditamos que essa aproximação é importante porque o ensino de ciências está vivenciando uma crise. Nas palavras de El-Hani:

"A crise contemporânea do Ensino de Ciências, evidenciada pelos altos índices de 'analfabetismo científico' e evasão de professores e alunos das salas de aulas de ciências, [...] contribuiu para que uma maior atenção recaísse sobre as abordagens contextuais do Ensino de Ciências."1

Sobre essa crise, Matthews afirma que:
"A história, a filosofia e a sociologia da ciência não têm todas as respostas para essa crise, porém possuem algumas delas: podem humanizar as ciências e aproximá-las dos interesses pessoais, éticos, culturais e políticos da comunidade; podem tomar as aulas de ciências mais desafiadoras e reflexivas, permitindo, deste modo, o desenvolvimento do pensamento crítico; podem contribuir para um entendimento mais integral de matéria científica, isto é, podem contribuir para a superação do mar de falta de significação que se diz ter inundado as salas de aula de ciências, onde fórmulas e equações são recitadas sem que muitos cheguem a saber o que significam; podem melhorar a formação do professor auxiliando o desenvol- vimento de uma epistemologia da ciência mais rica e mais autêntica, ou seja, de uma maior compreensão da estrutura das ciências bem como do espaço que ocupam no sistema intelectual das coisas."2

Assim, também acreditamos que a aproximação da história da ciência pode ser muito útil para melhorar a qualidade do ensino de ciências, pois, como apontado acima, abordagens contextuais podem ser o caminho para uma educação científica com mais qualidade. Nesse sentido, a história da ciência é uma área em expansão em todo o mundo, pois representa um espaço de reflexão e contextualização das ciências.

E quais são os motivos para essa crise? Sabemos que, aqui no Brasil, os motivos são muitos, entretanto, para não sermos demasiadamente rasos em nossa análise, tentaremos discutir a respeito de 
como o conteúdo científico é abordado em sala de aula. Nesse sentido, Soares aponta que o estudo formal desse conteúdo nos programas acadêmicos da atualidade apresenta três grandes problemas:

"Em primeiro lugar, sua desconexão, que obriga os alunos a tratar de distintas matérias como se fossem unidades isoladas em si mesmas. O saber aparece assim atomizado e descontínuo para o aluno, sem que este tenha, em algum momento, a oportunidade de entrever uma visão global ou de conjunto dos saberes científicos. Mediante esse tratamento fragmentado do conteúdo, seu intelecto vai se organizando em parcelas autônomas, carentes da necessária conexão e relação, levando-o a um modo deformado de entender a cultura, a ciência e a realidade.

Em segundo lugar, há a tendência de converter as ciências em simples saberes operativos. O saber científico é concebido como tendo apenas um caráter funcional e prático e, em correlação com esta visão, o professor tende a fazer com que o aluno aprenda primeiramente a operar e a formular e somente depois a compreender. As consequências imediatas de tal fazer geram nos estudantes uma carência de flexibilidade e de profundidade reflexiva e uma abundância de mecanização e memorização, cujo resultado último é a perda do sentido da aprendizagem. [...]

O estudante, deste modo, converte-se em um simples trabalhador braçal de resolução de problemas "de lápis e papel". [...]O terceiro é que, se bem que explicitamente o professor não ensine a história da ciência como tal, por outro lado, esta aflora implicitamente através de distintos conteúdos e o faz, na maioria das ocasiões, de forma desconexa e errada. O professor acaba transmitindo visões deformadas da ciência e dos cientistas, que acabam consolidando-os como estereótipos ou concepções ideológicas alienantes, difíceis de erradicar posteriormente." 3

Com relação a esse último problema - o de o professor ter e, portanto, transmitir, visões deformadas da ciência e dos cientistas para os alunos - apontado por Soares, Pérez nos traz um excelente levantamento da literatura, mostrando a importância de "(re)conhecer as visões deformadas dos professores sobre o trabalho científico". Ele nos aponta que existem sete visões deformadas amplamente mencionadas na literatura: ${ }^{4}$

1. “Concepção empírico-indutivista e ateórica": para Pérez, essa é a deformação mais apontada pela literatura (mais de 60 trabalhos no período de 1984-1998). É uma concepção que evidencia a suposta "neutralidade" da observação e da experimentação, esquecendo a importante função das hipóteses na orientação da investigação científica. Segundo ele, as concepções docentes são "marcadas por um empirismo extremo".

2. "[...] visão rígida (algorítmica, exata, infalível, [...] [da ciência])":essa é uma visão que, segundo Pérez, entende o método científico como um conjunto de passos para cumprir mecanicamente. Além disso, ela pode ser caracterizada por um forte apego ao tratamento quantitativo, ao controle rigoroso dos dados. Por outro lado, ela traz consigo uma certa recusa a tudo o que está relacionado à incerteza, à intuição, à criatividade, à reflexão, à ambiguidade e à dúvida. ${ }^{6}$

3. "Muito ligada a essa visão rígida, podemos mencionar a visão aproblemática e ahistórica (portanto, dogmática e fechada)": para Pérez, essa visão está ligada à transmissão dos conhecimentos já elaborados e prontos, sem mostrar os problemas que lhe deram origem, as dificuldades encontradas e os limites do conhecimento científico.? 4. "Uma deformação que apenas é mencionada pelos grupos de professores e que foi escassamente tratada pela investigação (menos de uma dezena de artigos lhe fazem referência) é a que consiste numa visão exclusivamente analítica [...]": ${ }^{8}$ aqui, Pérez ressalta a fragmentação dos estudos e o esquecimento do necessário esforço posterior de unificação e de construção de corpos coerentes de conhecimentos. 5. "[...] uma visão acumulativa de crescimento linear dos conhecimentos científicos [...]":de acordo com Pérez, essa visão ignora as crises e revoluções científicas, além de ser uma interpretação simplificada da transformação dos conhecimentos científicos, deixando de lado o confronto entre teorias rivais, as controvérsias científicas e os complexos processos de mudança conceitual, contribuindo para a mistificação do trabalho científico. ${ }^{9}$

6. "[...] uma visão individualista e elitista da ciência": ${ }^{10}$ nesse caso, segundo Pérez, essa visão deformada entende o conhecimento científico como fruto da obra de grandes gênios que trabalham de forma isolada, ignorando o trabalho colaborativo e coletivo da ciência. Esse tipo de visão traz consigo a ideia de que resultados isolados são suficientes para averiguar, provar ou refutar uma teoria. Nesse sentido, parece que o trabalho científico seja uma atribuição reservada a uma minoria dotada de dons especiais. Com isso, o aluno "normal" acaba por criar expectativas negativas em relação à ciência. A esse respeito, Pérez também aponta que:

"Contribui-se, além do mais, para esse elitismo escondendo o significado dos conhecimentos por meio de apresentações exclusivamente operativas. Não se faz um esforço para tornar a ciência acessível [...], nem para mostrar o seu carácter de construção humana, em que não faltam hesitações nem erros, situações semelhantes às dos próprios alunos."

7. "'[...] visão deformada que transmite uma imagem descontextualizada, socialmente neutra da ciência [...]": já essa visão deformada não permite, segundo Pérez, entender as complexas relações entre ciência, tecnologia e sociedade (CTS), gerando uma imagem deturpada dos cientistas. $^{12}$

Assim, Pérez também nos mostra que:

"Essas são, em síntese, as sete grandes visões deformadas que encontramos tratadas na literatura e que são mencionadas como fruto da reflexão e (auto)crítica dos grupos de professores. [...]

É preciso chamar a atenção para o fato de essas visões deformadas não constituírem uma espécie de "sete pecados capitais" diferentes e autônomos; antes, pelo contrário, [...] formarão um esquema conceptual relativamente integrado. Parece razoável, por exemplo, que uma visão individualista e elitista da ciência apoie implicitamente a ideia empirista de "descoberta" e contribua, além do mais, para uma leitura descontextualizada e socialmente neutra da atividade científica (realizada por "gênios" solitários). Do mesmo modo, para citar outro exemplo, uma visão rígida, algorítmica e exata da ciência pode reforçar uma interpretação acumulativa e linear do desenvolvimento científico, ignorando as crises, as controvérsias e as revoluções científicas." ${ }^{13}$

Apontamos até aqui alguns dos principais problemas que contribuem para a crise no ensino de ciências. Então, neste momento, gostaríamos de destacar nossa segunda questão: Qual o papel da história da ciência no ensino de ciências?

Acreditamos que a história da ciência possa funcionar como um ótimo "remédio" para amenizar cada um dos três problemas apontados por Soares ${ }^{14} \mathrm{e}$ também para as visões deformadas apontadas por Pérez. Martins nos traz uma discussão bem detalhada a esse respeito. De 
acordo com ele: "A história das ciências não pode substituir o ensino comum de ciências, mas pode complementá-lo de várias formas". ${ }^{15}$ Para ele, o estudo adequado (e, portanto, aprofundado) de alguns episódios históricos permite compreender:

- 1. “[que os] pesquisadores formulam hipóteses ou conjeturas [...], têm ideias preconcebidas ao fazerem suas observações e experimentos, $[\ldots]$ "

- 2. "[...] que a ciência não é resultado da aplicação de um "método científico" que permita chegar à verdade. [...]. As teorias científicas vão sendo construídas [...] [e] elas podem chegar a se tornar bem estruturadas e fundamentadas, mas jamais podem ser provadas. O processo científico é extremamente complexo, não é lógico e não segue nenhuma fórmula infalível."

- 3. "[...] o processo gradual de formação de teorias, modelos, conceitos [...]; a existência de teorias alternativas, de controvérsias, [...]"

- 4. "[...] a natureza das ciências, suas limitações, suas relações com outros domínios."

- 5. "[...] [o papel das] revoluções que lançam por terra concepções que eram aceitas [...] durante muito tempo; a permanência de dúvidas mesmo com relação a teorias bem corroboradas; a influência de concepções filosóficas, religiosas [...]; e muitos outros aspectos da dinâmica da ciência." - 6. “[...] uma visão mais concreta e correta da real natureza da ciência, seus procedimentos e suas limitações - o que contribui para a formação de um espírito crítico e desmitificação do conhecimento científico, sem, no entanto, negar seu valor. A ciência não brota pronta, na cabeça de "grandes gênios"." - 7. "[...] as interrelações entre ciência, tecnologia e sociedade, mostrando que a ciência não é uma coisa isolada de todas as outras, mas sim faz parte de um desenvolvimento histórico, de uma cultura, de um mundo humano, sofrendo influências e influenciando por sua vez muitos aspectos da sociedade."16

Nesse momento, é particularmente interessante notar que Martins, de certa forma, indica que o estudo adequado de episódios históricos pode contribuir como um "remédio" para amenizar quase todos os problemas apontados por Soares e Pérez. Uma leitura atenta comparando os dizeres de ambos nos permite inferir isso.

Martins também sinaliza que, no Brasil e no mundo, os educadores perceberam a importância da história da ciência para o ensino de todos os níveis, e que no Brasil, nos últimos anos, os Parâmetros Curriculares Nacionais (PCN) para o ensino médio enfatizaram muito a pertinência da história da ciência para complementar outras abordagens no ensino científico. ${ }^{17}$

Entretanto, segundo ele, existem três principais problemas para que a história da ciência desempenhe seu papel no ensino: (1) a carência de professores com boa formação em história da ciência, (2) a falta de bons materiais didáticos de história da ciência que possam ser usados no ensino, e (3) o não entendimento sobre a natureza da própria história da ciência e seu uso na educação, ou seja, o uso equivocado da história da ciência no ensino, reduzindo a história da ciência a um amontoado de nomes, datas, anedotas e argumentos de autoridade. ${ }^{18}$

O presente trabalho traz um episódio histórico para que possa ser utilizado no ensino de química, portanto, pretende contribuir para minimizar o problema (2) da falta de material didático adequado.

É oportuno considerarmos, agora, a questão três: Como de fato podemos utilizar história da ciência nas aulas de química do ensino médio? Para tentarmos responder a essa pergunta mais geral, gostaríamos de propor questões mais específicas. Primeiramente, se a história da ciência pode ser um "remédio" para o ensino de química, então qual seria a "dose" desse "remédio"? Segundo, como trabalharíamos esses episódios de história da química nas aulas de química?

Pensando um pouco a respeito de qual seria a dose de história da ciência, gostaríamos de, primeiramente, recordar a opinião de Martins, o qual acredita que a história da ciência não pode substituir o ensino comum de ciências, mas pode complementá-lo. ${ }^{19}$ Compartilhamos da mesma opinião e, isso posto, acreditamos que durante o ensino médio, na disciplina de química, seria muito proveitoso que o aluno pudesse ter o contato com alguns episódios de história da química. Mas quantos e quais episódios?

Consideramos que um critério interessante para selecionarmos os episódios seria o de usar a ideia de "conceitos estruturantes". De acordo com Gagliardi:

“[...] os conceitos estruturantes [são aqueles] que permitiram a transformação de uma ciência, a elaboração de novas teorias, a utilização de novos métodos e novos instrumentos conceituais." 20

Nessa perspectiva, esses conceitos são conceitos-chave, ou seja, concepções que formam o alicerce e dão a sustentação conceitual para as ciências de hoje. Olhando para a química moderna, podemos identificar alguns deles, a saber: átomo, mol, molécula, reação química, misturas etc.

Assim, podemos usar em sala de aula episódios de história da química que tratam da gênese desses conceitos, das muitas concepções e discussões que se sucederam nos diferentes contextos e das transformações conceituais ocorridas ao longo do tempo. Portanto, talvez não seja interessante usar qualquer episódio de história da química no ensino, mas, sim, episódios que tratem, de alguma maneira, de conceitos estruturantes em química. Assim, o presente trabalho utilizou a noção de conceitos estruturantes como critério de escolha do episódio histórico desenvolvido.

Já quanto à questão de como trabalharíamos os episódios de história da química nas aulas de química, gostaríamos de responder a essa pergunta utilizando um pouco da nossa prática de sala de aula. ${ }^{21}$ A partir de nossa experiência, pudemos constatar que duas estratégias pedagógicas ${ }^{22}$ são interessantes para a inserção de episódios de história da química em sala de aula. Em primeiro lugar, a partir de um bom material de história da ciência (artigos, dissertações de mestrado, teses de doutorado), o professor monta a sua aula teórica com slides. A outra estratégia interessante é a de disponibilizar o material de história da ciência para que o aluno possa ler em sala de aula, e posteriormente o professor possa conduzir a discussão. Nas duas formas de trabalho é interessante que o professor, a partir do episódio histórico, evidencie o processo de construção do "conceito estruturante", além de outros aspectos interessantes sobre a natureza da ciência. ${ }^{23}$

O presente artigo traz um episódio histórico que pode ser aplicado em sala de aula utilizando qualquer uma das duas estratégias pedagógicas indicadas acima.

Para finalizarmos esta seção, gostaríamos de evidenciar a dificuldade de pensar a possibilidade da interface entre história da ciência e ensino, pois a construção das narrativas históricas deve ser adequada ao ambiente escolar. Isso significa que ela deve ser cuidadosamente construída, de modo a, por um lado, estar alinhada com pressupostos básicos e recomendações da historiografia contemporânea, tomando o devido cuidado para não recorrer à pseudo-história e análises anacrônicas; e, por outro, estar alinhada com os pressupostos básicos da didática, de modo que a narrativa construída não seja desinteressante e incompreensível ao aluno do ensino básico, respeitando o tempo didático e as particularidades da escola básica, com seus problemas estruturais e conjunturais. ${ }^{24}$ 


\section{O EPISÓDIO HISTÓRICO - ESTUDO SOBRE A INVENÇÃO DA TEORIA ATÔMICO-MOLECULAR MODERNA}

\section{A publicação de Dalton em 1808 e a teoria dos pesos atômicos}

Em 1808, John Dalton (1766-1844) publicou a primeira parte do volume 1 de sua mais famosa obra, A new system of chemical philosophy. Ao final desse trabalho, ele estabeleceu os princípios que nortearam sua teoria dos pesos atômicos. Ao examinarmos atentamente essa obra, percebemos que ele determinou os pesos das partículas a partir dos resultados experimentais ${ }^{25}$ de sínteses e decomposições químicas das substâncias, usando e estendendo os dados gravimétricos da balança para os átomos. Dalton afirma que: “[...] dos pesos relativos em massa, os pesos relativos das partículas últimas ou átomos dos corpos poderiam ter sido inferidos, [...]". ${ }^{26}$

Além disso, para poder estabelecer esses pesos, Dalton usou como pressuposto a regra de máxima simplicidade - que é uma regra de combinação, ou um princípio assumido sem provas - que orienta a proporção e o número de átomos que formam uma partícula (molécula nos termos de hoje). A regra de máxima simplicidade assumida por Dalton é explicitada como segue:27

"Se houver dois corpos, A e B, que estão dispostos a se combinar, a ordem em que as combinações acontecem é a seguinte, começando com o mais simples:

a saber,

1 átomo de $\mathrm{A}+1$ átomo de $\mathrm{B}=1$ átomo de $\mathrm{C}$, binário

1 átomo de $\mathrm{A}+2$ átomos de $\mathrm{B}=1$ átomo de $\mathrm{D}$, ternário

2 átomos de $\mathrm{A}+1$ átomo de $\mathrm{B}=1$ átomo de $\mathrm{E}$, ternário

1 átomo de $\mathrm{A}+3$ átomos de $\mathrm{B}=1$ átomo de $\mathrm{F}$, quaternário

3 átomos de $\mathrm{A}+1$ átomo de $\mathrm{B}=1$ átomo de $\mathrm{G}$, quaternário [e assim por diante]

Podem ser adotadas as seguintes regras gerais como guias em todas as nossas investigações respeitando a síntese química. 1. Quando só uma combinação de dois corpos pode ser obtida, presume-se que seja binária, a menos que alguma causa pareça o contrário

2. Quando duas combinações [entre dois corpos] são observadas, presume-se que elas sejam uma binária e uma ternária. 3. Quando três combinações [entre dois corpos] são obtidas, podemos esperar uma como sendo binária e as outras duas ternárias.

4. Quando quatro combinações [entre dois corpos] são observadas, nós devemos esperar uma binária, duas ternárias e uma quaternária, [e assim por diante]

5. Um composto binário deve sempre ser especificamente mais pesado [mais denso] do que uma mera mistura dos dois ingredientes.

6. Um composto ternário deve ser especificamente mais pesado [mais denso] do que a mistura de um binário e um simples, [...]; [e assim por diante].

7. As regras e observações acima aplicam-se, igualmente, quando dois corpos, tais como "C" e "D", "D" e "E" etc.,são combinados. [...] [continua]." 28

Como exemplo, veremos de que maneira Dalton determinou o peso dos átomos de hidrogênio e de oxigênio. Ele primeiramente prefixou o hidrogênio como sendo de peso relativo 1 . Ao que tudo indica, essa predeterminação se deu a partir do resultado das combinações do hidrogênio com diversos outros elementos nas mais diversas substâncias. Por meio dessas combinações, Dalton percebeu que em todas as reações de que participava, era o que se encontrava sempre na menor proporção em massa na formação dos compostos. Além disso, o hidrogênio era o gás de menor densidade entre os gases. Possivelmente, essas evidências levaram Dalton a concluir que o hidrogênio deveria ser o elemento "mais leve" e, portanto, o átomo de menor peso que existe. Ele adotou, então, o hidrogênio como padrão de referência nas combinações, atribuindo seu peso relativo como sendo 1 (um). ${ }^{29}$

Por outro lado, na determinação do peso do átomo de oxigênio, Dalton usou os resultados experimentais - de Joseph Louis GayLussac (1778-1850) e Alexander Von Humboldt (1769-1859) - da composição gravimétrica da água. Nesse caso, 100 unidades de massa de água geram 12,6 de hidrogênio e também 87,4 de oxigênio. Desse modo, a partir dos dados vemos que a massa de oxigênio é, aproximadamente, sete vezes maior que a de hidrogênio, pois: $(87,4 \div 12,6=7)$. Naquela época, Dalton conhecia apenas a água como sendo formada por hidrogênio e oxigênio, o que, a partir do item 1 da regra de máxima simplicidade, o levou a concluir que a partícula de água era binária, ou seja, composta por apenas um átomo de hidrogênio e um de oxigênio. ${ }^{30}$

De posse desses dois dados, um obtido pela balança, o macroscópico, o outro conseguido por meio de um raciocínio de simplicidade, que permitiu imaginar o mundo microscópico, Dalton inferiu, generalizou ou estendeu os dados da balança para os átomos, conforme disposto a seguir:

"Determinados os pesos absolutos de oxigênio e hidrogênio na água, os pesos relativos dos seus átomos podem ser investigados. Como apenas um composto de oxigênio e hidrogênio é certamente conhecido, é aceitável a $1{ }^{\text {a }}$ regra, ${ }^{31}$ página 214 , conclui-se que a água deve ser um composto binário; ou, um átomo de oxigênio une-se a um de hidrogênio para formar um de água. Consequentemente, os pesos relativos dos átomos de oxigênio e hidrogênio são 7 para 1., ${ }^{32}$

Dessa maneira, Dalton queria explicar a constituição gravimétrica não só da água, mas também das demais substâncias. Nesse empreendimento, ele determinou os pesos atômicos relativos para muitos outros átomos e, em todos os casos, usou a mesma metodologia de trabalho, ou seja, generalizou os dados da balança para os átomos usando a regra de máxima simplicidade para definir o número de átomos na molécula.

Vejamos agora mais um exemplo no qual Dalton determinou o peso de um átomo. O átomo escolhido é o de nitrogênio, e em nossa discussão iremos levar em conta apenas os dados gravimétricos dos óxidos de nitrogênio e da amônia.

Os três principais óxidos de nitrogênio, naquela época, e suas composições gravimétricas estão descritas abaixo (Tabela 1):

De acordo com Dalton, a densidade desses gases aumentava do primeiro para o último, então, segundo a regra de máxima simplicidade, o gás nitroso era binário e os outros dois óxidos de nitrogênio eram ternários. Para Dalton, o óxido nitroso era o $\mathrm{N}_{2} \mathrm{O}$ e o ácido nítrico o $\mathrm{NO}_{2} \cdot{ }^{35}$ Mas, como ele conseguiu discernir qual óxido ternário era o $\mathrm{N}_{2} \mathrm{O}$ e qual era o $\mathrm{NO}_{2}$ ?

Para tentarmos responder a essa pergunta e entendermos as interpretações atômicas de Dalton, vamos observar a Tabela 1. Quando olhamos os dados do gás nitroso NO, a razão entre os átomos $(\mathrm{N} \div 7=0,87)$ tem que ser a mesma daquela obtida pela experiência $(46,6 \div 53,4=0,87)$, ou seja, 0,87 . O resultado para o átomo de nitrogênio nesse caso deu 6,1. Assim, podemos constatar, a partir dos dados do gás nitroso, que o átomo de nitrogênio $(6,1)$ é ligeiramente "mais leve" que o de oxigênio (7), portanto, a molécula de $\mathrm{N}_{2} \mathrm{O}$ deve ser ligeiramente "mais leve" que a de $\mathrm{NO}_{2}$. Essas diferenças de peso molecular têm uma manifestação macroscópica por meio 
Tabela 1. Comparação entre a constituição gravimétrica de 100 unidades de massa dos óxidos de nitrogênio com a interpretação atômica de John Dalton ${ }^{33}$

\begin{tabular}{|c|c|c|c|c|c|}
\hline \multirow{2}{*}{ Substância } & \multicolumn{3}{|c|}{ Resultados experimentais da constituição em massa dos óxidos de nitrogênio } & \multicolumn{2}{|c|}{ Interpretação atômica de Dalton } \\
\hline & Nitrogênio & Oxigênio & Razão experimental & Razão entre os átomos & Peso do átomo de nitrogênio \\
\hline Gás nitroso & 46,6 & 53,4 & $46,6 \div 53,4=0,87$ & $\mathrm{~N} \div 7=0,87$ & 6,1 \\
\hline Óxido nitroso & 63,5 & 36,5 & $63,5 \div 36,5=1,74$ & $(2 \times N) \div 7=1,74$ & 6,1 \\
\hline Ácido nítrico ${ }^{34}$ & 29,6 & 70,4 & $29,6 \div 70,4=0,42$ & $N \div(2 \times 7)=0,42$ & 5,9 \\
\hline
\end{tabular}

da densidade, e, nesse sentido, o óxido nitroso é o $\mathrm{N}_{2} \mathrm{O}$, e o ácido nítrico, que é o composto mais denso, é o $\mathrm{NO}_{2}$.

Tudo o que foi apresentado anteriormente pode ser corroborado quando analisamos apenas os resultados experimentais. No gás nitroso, as quantidades de nitrogênio e oxigênio são muito parecidas devido aos pesos dos átomos, que são muito semelhantes. Quando olhamos apenas para os resultados experimentais da composição gravimétrica do óxido nitroso, vemos que a quantidade de nitrogênio é muito maior do que a de oxigênio, o que nos leva a pensar que a molécula deva ser $\mathrm{N}_{2} \mathrm{O}$. Já no caso do ácido nítrico ocorre o contrário. Em sua composição gravimétrica, observamos que a quantidade de oxigênio é muito maior que a de nitrogênio, nos levando a concluir que a molécula deva ser $\mathrm{NO}_{2}$.

Observemos agora de que forma Dalton calculou o peso relativo para o nitrogênio no óxido nitroso e no ácido nítrico.

No caso do óxido nitroso, a razão entre os átomos $((\mathrm{Nx} 2) \div 7=1,74)$ deve ser a mesma daquela obtida pela experiência $(63,5 \div 36,5=1,74)$, ou seja, 1,74 . O resultado para o átomo de nitrogênio nesse caso deu 6,1 .

Quanto aos dados do ácido nítrico, a razão entre os átomos $(\mathrm{N} \div(7 \times 2)=0,42)$ deve ser a mesma daquela obtida pela experiência $(29,6 \div 70,4=0,42)$. O resultado para o átomo de nitrogênio nesse caso deu próximo de 6 , conforme a tabela acima.

Até o presente momento, estamos demonstrando apenas os dados e aspectos coerentes da teoria atômica de Dalton, pois, quando olhamos para o peso do átomo de nitrogênio a partir dos dados da experiência dos óxidos de nitrogênio, todos os resultados apontam para um nitrogênio pesando em torno de 6 . Acontece que, para que a teoria atômica seja razoável, é preciso que o peso do átomo de nitrogênio esteja por volta de 6 em qualquer situação, não importando de onde venha esse nitrogênio. Logo abaixo está a composição gravimétrica da amônia e a interpretação atômica de Dalton na determinação do peso relativo do nitrogênio (Tabela 2):

No caso da amônia, naquele momento, Dalton conhecia apenas uma substância formada apenas por nitrogênio e hidrogênio, portanto, de acordo com a regra de máxima simplicidade, a amônia deveria ser um composto binário, ou seja, formada por um átomo de nitrogênio e por um de hidrogênio. Como assumimos que o peso do hidrogênio é 1 , e a razão entre as massas do experimento deu 4,2 $(121 \div 29=4,2)$, para calcularmos o peso do átomo de nitrogênio a conta que deve ser feita é $(\mathrm{N} \div 1=4,2)$, chegando ao peso do nitrogênio como sendo 4,2 .

Esses dados trazem sérios problemas para o sistema de cálculo dos pesos atômicos de Dalton, pois o nitrogênio originado dos óxidos nos leva a crer que o átomo de nitrogênio pesa em torno de 6 , já o nitrogênio proveniente da amônia nos aponta que o átomo de nitrogênio deve pesar por volta de 4 . As pequenas variações no peso do nitrogênio que vêm dos óxidos $(6,1,6,1$ e 5,9) são, talvez, justificáveis por "flutuações naturais" das medidas experimentais, mas, quando olhamos para o nitrogênio ora pesando 6, ora pesando 4, a diferença é bastante significativa e Dalton percebeu isso. Ele sabia que sua teoria atômica tinha problemas, tanto que, para minimizá-los, escolhia os dados experimentais que mais lhe convinham. No caso do nitrogênio, por exemplo, ele preferia escolher dados de seus contemporâneos, que superestimavam a massa do nitrogênio proveniente da amônia, e dados que minimizavam a massa do nitrogênio originado dos óxidos de nitrogênio. Por isso, ele conseguia supor que a massa de nitrogênio estaria perto de 5 para ambos os casos. ${ }^{37}$

Dalton sabia dos problemas de sua teoria, tendo em vista que mudava constantemente os valores dos pesos atômicos (Tabela 3).

Segue uma lista de pesos atômicos de seu trabalho de 1827 (Figura 1).

Nessa lista, Dalton salientou que o átomo de nitrogênio (Azote) deve pesar mais ou menos 5 ou 10, além disso, podemos constatar que ele tinha dúvidas quanto ao peso de vários elementos, pois ele colocou ponto de interrogação, demonstrando desconfiança a respeito do real valor.

Assim, apesar de saber que sua teoria atômica tivesse muitos problemas, Dalton acreditava nela, posto que a lista acima é do ano de 1827, ou seja, 24 anos depois do seu primeiro anúncio dos pesos atômicos. Sendo assim, Dalton sabia que seu trabalho era importante e, apesar dos problemas, não abandonou suas ideias!

\section{A publicação de Gay-Lussac em 1809 e a resposta de Dalton em 1810}

Em 1809, Gay-Lussac, que era reconhecido como um habilidoso experimentalista, publicou dois importantes trabalhos, o Mémoire sur la combinaison dês substances gazeuses, les unes avec lês autres e o Sur La vapeur nitreuse, et sur le gaz, nitreux considere comme moyen eudiométrique. No primeiro artigo, ele anunciou sua importante lei da combinação gasosa:

"Assim, parece-me óbvio que todos os gases que atuam um sobre o outro, sempre se combinam em relações simples e, de fato, vimos em todos os exemplos anteriores que a razão de combinação é de 1 para 1 de 1 para 2 ou de 1 a 3 ". ${ }^{40}$

No segundo trabalho, ele resumiu em uma lista alguns dos seus principais resultados que o levaram a enunciar tal lei. A lista nos traz dezoito substâncias e suas constituições volumétricas. A título de exemplo, temos a amônia, que, segundo Gay-Lussac, é constituída por 100 partes de nitrogênio e 300 de hidrogênio. É curioso notarmos que para todas as substâncias na lista, as proporções de

Tabela 2. Comparação entre a constituição gravimétrica de 150 unidades de massa da amônia com a interpretação atômica de John Dalton ${ }^{36}$

\begin{tabular}{|c|c|c|c|c|c|}
\hline \multirow[t]{2}{*}{ Substância } & \multicolumn{3}{|c|}{ Resultados experimentais } & \multicolumn{2}{|c|}{ Interpretação atômica de Dalton } \\
\hline & Nitrogênio & Hidrogênio & Razão experimental & Razão entre os átomos & Peso do átomo de nitrogênio \\
\hline Amônia & 121 & 29 & $121 \div 29=4,2$ & $\mathrm{~N} \div 1=4,2$ & 4,2 \\
\hline
\end{tabular}


Tabela 3. Histórico dos valores dos pesos atômicos ${ }^{38}$

\section{VALORES E FONTES DOS PESOS ATÔMICOS}

\begin{tabular}{|c|c|c|c|c|c|c|c|c|c|c|c|c|}
\hline ÁTOMOS & 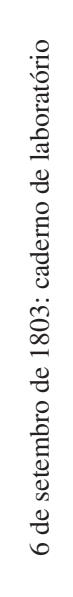 & 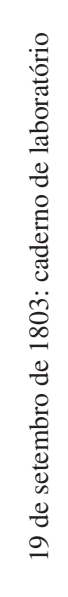 & 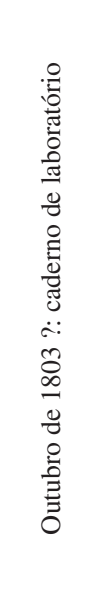 & 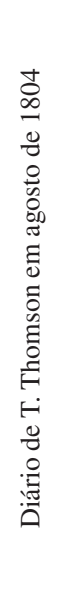 & 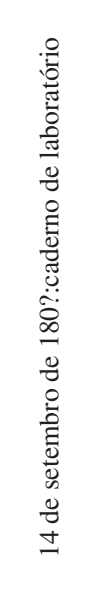 & 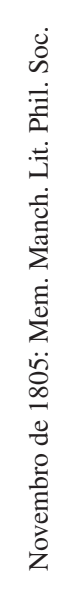 & 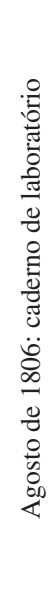 & 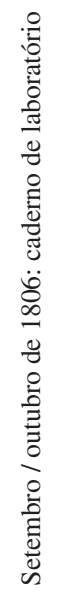 & 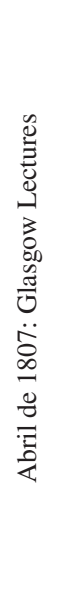 & 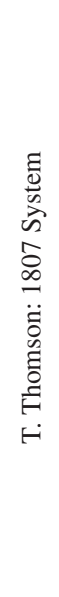 & 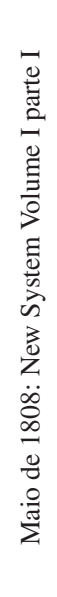 & 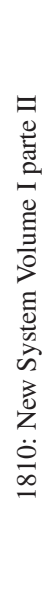 \\
\hline Hidrogênio & 1 & 1 & 1 & 1 & 1 & 1 & 1 & 1 & 1 & 1 & 1 & 1 \\
\hline Oxigênio & 5,66 & 5,66 & 5,5 & 6,5 & 5,5 & 5,5 & 7 & 7 & 7 & 6 & 7 & 7 \\
\hline Azoto ou Nitrogênio & 4 & 4 & 4 & 5 & 4,2 & 4,2 & 5 & 5 & 5 & 4,5 & 5 & 5 \\
\hline Enxofre & 17 & 14,4 & {$[14,4]$} & - & {$[14,4]$} & 14,4 & 22 & 12 & 13 & - & 13 & 13 \\
\hline Fósforo & - & 7,2 & {$[7,2]$} & - & - & 7,2 & $9+$ & 9,3 & 9 & - & 9 & 9 \\
\hline
\end{tabular}

\begin{tabular}{|c|c|}
\hline Heights & \\
\hline Iydrogen................... & Strontium .. \\
\hline Azote..........5 土, or 10 ? & Antimony ... \\
\hline Carbone $\quad \ldots \ldots \ldots \ldots \ldots \ldots .5 .4$ & Iridium $\ldots \ldots \ldots \ldots$ \\
\hline Oxygen..................7 & Palladium ..............50 \\
\hline Phosphorus .............99 & Craniuen .....50, or 100 ? \\
\hline$\ldots \ldots \ldots 13$, or 14 & Tin .....................52 \\
\hline Calcium ...............17? & Copper.........56, or 28 ? \\
\hline Bodium ............ & Rliodium $\quad \ldots \ldots \ldots \ldots \ldots 6$ \\
\hline Arsenic $\ldots \ldots \ldots \ldots \ldots \ldots . . .21$ & Titanium $\ldots . \ldots \ldots \ldots \ldots$.....59 \\
\hline Molybdenum ...21, or 42? & Gold $\ldots \ldots \ldots \ldots \ldots \ldots \ldots 60$ 土. \\
\hline Cerium $\ldots \ldots \ldots \ldots \ldots \ldots . . \ldots 22$ ? & Barium ...............61 \\
\hline Iron................ & Bismuth ...............62 \\
\hline Manganese ...... & ...........73 \\
\hline Nickel............ & Tungsten........84, or 42 ? \\
\hline Zine $\quad \ldots . . . \ldots \ldots \ldots \ldots . . .29$ & Silver ...................90 \\
\hline Tellurium $\quad \ldots . .29$, or 58 ? & $\ldots \ldots \ldots \ldots \ldots .90$ \\
\hline Chromium ..............32 & Columbium ..107? 121? \\
\hline Potanium ........ & Mercury........167, or 84 ? \\
\hline
\end{tabular}

Cobalt.
“[...] a opinião [de Gay-Lussac] baseia-se numa hipótese de que todos os gases se combinam em medidas iguais ou em medidas que têm alguma relação simples um para com o outro, como 1 para 2,1 para 3,2 para 3, etc.

$\mathrm{Na}$ verdade, sua noção de medidas [para volumes dos gases] é análoga à minha para átomos; e se pudesse provar que todos os gases têm o mesmo número de átomos no mesmo volume, $[\ldots]$ as duas hipóteses seriam a mesma [...]". ${ }^{44}$

O que Dalton estava tentando nos dizer é que se por um lado os átomos se combinavam em proporções simples, como ilustramos em "A", e, por outro, os volumes dos gases também se combinavam em proporções simples, ilustrado em $\mathrm{B}$, então podia-se inferir $\mathrm{C}$, conforme Figura 2 abaixo:

Já refletimos muito sobre isso e nos parece que Dalton inferiu precipitadamente que caso a lei volumétrica de Gay-Lussac estivesse correta, todos os gases possuiriam o mesmo número de átomos em um mesmo volume a uma dada condição de temperatura e pressão. De qualquer modo, Dalton continuou seu argumento:

“Gay-Lussac, não pude deixar de ver ( página 188, parte 1 desse trabalho) que uma hipótese semelhante havia sido considerada por mim e abandonada como insustentável; no entanto, como ele retomou a questão, vou fazer algumas observações sobre ela, [...] [e] ele logo verá a sua inadequação." ${ }^{\prime 6}$

Ao consultarmos a página 188, nota-se Dalton afirmando que:

"Na época que formulei a teoria das misturas gasosas, eu como muitos, tinha uma ideia confusa. Eu supus nessa época que as partículas dos fluidos elásticos eram todas do mesmo tamanho; que um dado volume de gás oxigênio continha tantas partículas quanto o mesmo volume de hidrogênio; [...] Mas através de uma sequência de raciocínios similares àquele exibido na página 71 , me convenci que os diferentes gases não tinham suas partículas do mesmo tamanho [....]." ${ }^{37}$ 


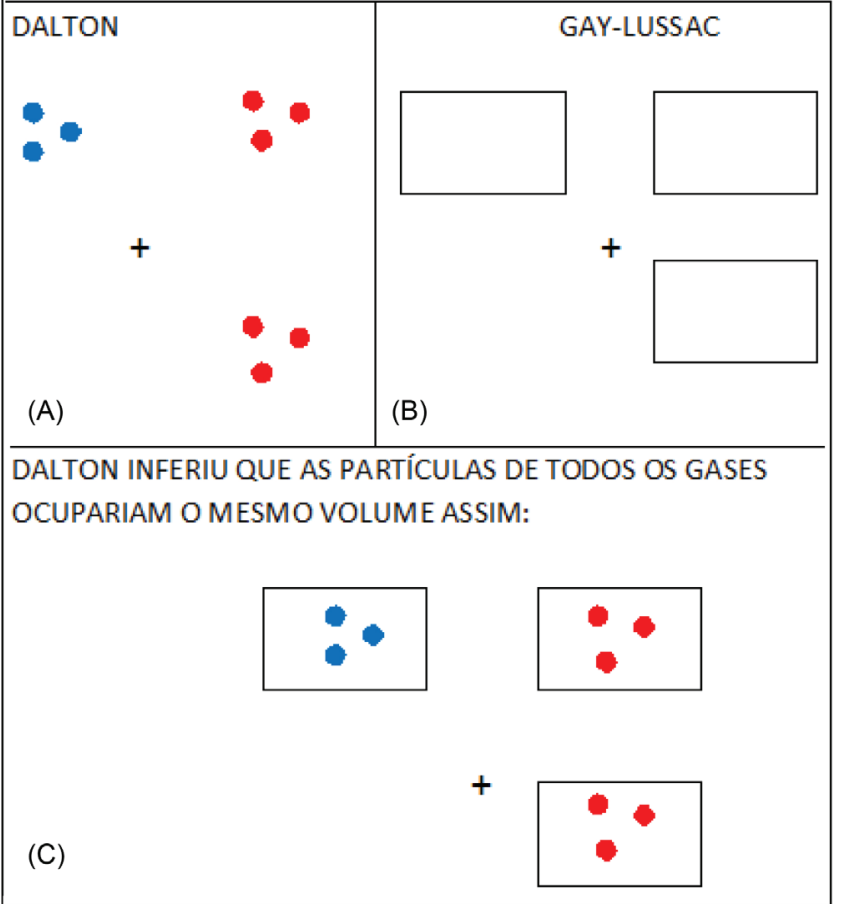

Figura 2. Ilustração do argumento de Dalton ${ }^{45}$

Mas qual seria essa sequência de raciocínios a qual Dalton se refere? Consultando a página 71 , encontramos os seguintes dizeres:

"É evidente que o número das últimas partículas ou moléculas em um dado [...] volume de um gás não é o mesmo quanto em outro [gás]: pois, se medidas iguais de nitrogênio e oxigênio forem misturadas, e pudessem ser instantaneamente unidas quimicamente, elas formariam praticamente duas medidas de gás nitroso, [...]; mas o número das últimas partículas diminuiria pela metade daquele antes da união química. Portanto, provavelmente, dois fluídos elásticos (gases) não tem o mesmo número de partículas [...] no mesmo volume [...]." ${ }^{, 8}$

A figura abaixo nos mostra mais claramente o que Dalton está tentando evidenciar (Figura 3):

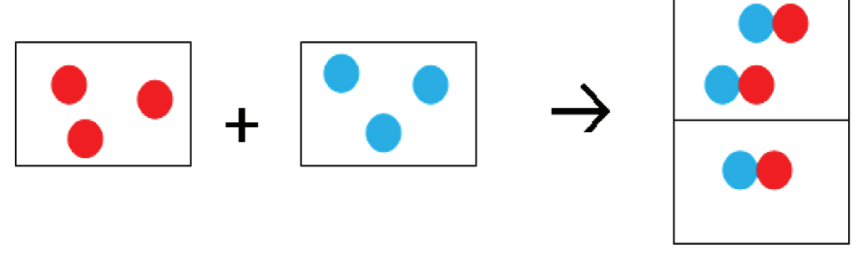

Figura 3. Combinação entre nitrogênio e oxigênio na formação de gás nitroso (nosso monóxido de nitrogênio) e interpretação atômica de Dalton ${ }^{49}$

Experimentalmente, segundo Dalton, quando um volume de nitrogênio reage com um volume de oxigênio, são formados dois volumes de gás nitroso, como nos mostra o trecho da citação acima. Então, vamos supor uma situação em que um volume de nitrogênio a uma dada temperatura e pressão, tenha três átomos (representados por três esferas vermelhas) - reaja com um volume de oxigênio (três esferas azuis). São formados dois volumes de gás nitroso (três pares de esferas vermelhas e azuis) conforme ilustração acima. Acontece que, antes da reação, temos dois volumes para seis partículas (três de nitrogênio e três de oxigênio). Depois da reação, temos os mesmos dois volumes, só que agora com apenas três partículas compostas de gás nitroso, ou seja, com a metade das partículas antes da união química. Desse modo, a partícula de gás nitroso ocupa um volume que é o dobro das partículas de nitrogênio e oxigênio.

Esse argumento de Dalton é muito interessante, pois, por meio de um exemplo, ele nos prova a impossibilidade da existência do mesmo número de átomos em um mesmo volume em diferentes gases.

Então, como pudemos ver a partir das últimas três citações, Dalton estava extremamente interessado em negar as leis volumétricas de Gay-Lussac. Abaixo, seguem mais trechos nos quais Dalton tentou desqualificar "as leis volumétricas" de Gay-Lussac:

\begin{abstract}
"Algumas observações sobre o ácido nítrico, e outros compostos de nitrogênio e oxigênio têm sido feitas por Gay-Lussac, no segundo volume das Mémoires d'Arcueil. Ele afirma que uma medida de gás oxigênio se une com duas medidas de gás nitroso para formar ácido nítrico [...]. Agora eu tenho mostrado, página328, que uma medida de oxigênio pode se combinar com 1,3 de gás nitroso [...]." ${ }^{50}$
\end{abstract}

Mais adiante, no mesmo texto:

"Há outro ponto de vista em que esta teoria de Gay-Lussac é infeliz, em relação à amônia [...], [para ele] 1 medida de nitrogênio com 3 de hidrogênio, forma 2 de amônia; [...]. Se Gay-Lussac adotar minhas conclusões, [...] [verá] que 100 medidas de nitrogênio requerem cerca de 250 de hidrogênio para formar amônia, [...]." ${ }^{51}$

Constatamos aqui que Dalton estava contrapondo seus dados aos de Gay-Lussac para tentar invalidar "as leis volumétricas", concluindo que:

"A verdade é, creio eu, que os gases não se unem em medidas iguais ou exatas em qualquer instância; quando isso acontece, é devido à inexatidão de nossos experimentos." ${ }^{52}$

Nesse momento, é interessante questionar o porquê "as leis volumétricas" de Gay-Lussac tanto incomodaram Dalton?

Como já apresentado anteriormente, Dalton precipitadamente inferiu que caso a lei de Gay-Lussac estivesse correta, então todos os gases possuiriam o mesmo número de átomos em um dado volume em uma certa condição de temperatura e pressão. Ele logo notou que essa conclusão trazia grandes problemas para suas ideias, pois, por um lado invalida a sua teoria das misturas dos gases que está baseada no fato de os gases terem átomos de tamanhos diferentes. ${ }^{53}$ Por outro lado, viola a sua própria teoria atômica, quando olhamos de perto o seu argumento da página 71 e a figura 3 de nosso trabalho, e também todo o seu esforço para criar um sistema de cálculo para os diâmetros e volumes dos átomos e explicar as relações volumétricas das reações químicas. ${ }^{54}$

Um outro exemplo que podemos criar para ilustrar o quanto "as leis volumétricas" - e sua interpretação equivocada por parte de Dalton - trazem de inconsistências para a teoria atômica é o caso da água.

Experimentalmente, segundo Gay-Lussac, quando dois volumes de hidrogênio reagem com um volume de oxigênio, são formados dois volumes de vapor d'água. Então, vamos supor uma situação em que dois volumes de hidrogênio - a uma dada temperatura e pressão, tenham seis átomos (representados por seis esferas azuis, ou seja, três esferas para cada volume) - reajam com um volume de oxigênio (contendo três esferas vermelhas). Empiricamente, sabemos que são formados dois volumes de vapor d'água. Acontece que, para que isso ocorra, respeitando que todo gás possua o mesmo número 
de partículas em um mesmo volume (três partículas para cada volume), os átomos de oxigênio deveriam se dividir ao meio conforme a ilustração abaixo (Figura 4):

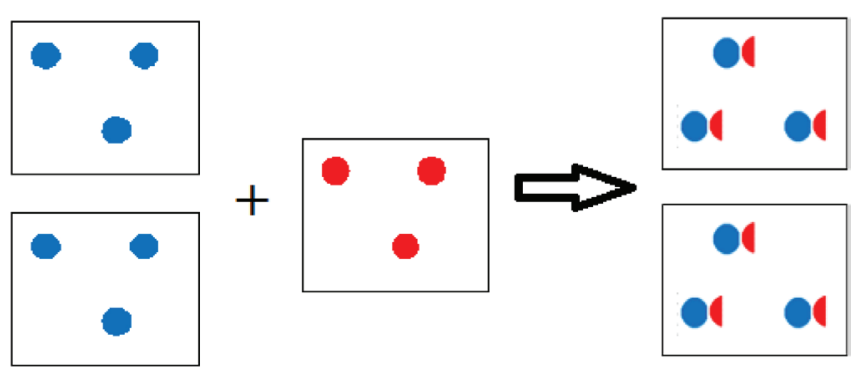

Figura 4. Representação da formação da água tomando como pressuposto de que todos os gases possuem o mesmo número de partículas em um mesmo volume $e^{55}$

Isso traz inconsistência à teoria atômica de Dalton, que pensa o átomo como sendo indivisível.

Então, como pudemos ver, naquele momento, em 1810, "as leis volumétricas" de Gay-Lussac, interpretadas por meio das ideias de Dalton e tendo como pressuposto que todos os gases possuem o mesmo número de átomos em um dado volume, traziam grandes problemas para a teoria atômica de Dalton.

\section{A proposta de Avogadro em 1811}

Em 1811, Lorenzo Romano Amedeo Carlo Avogadro (1776-1856) publicou um importante trabalho, o d'une manière de déterminer lês masses relatives dês molécules élémentaires dês corps, et lês proportions selon lesquelles elles entrent dans ces combinaisons no Journal de Physique. Nessa obra, é nítida a influência dos trabalhos de Dalton e Gay-Lussac sobre as ideias de Avogadro. ${ }^{56}$

Ao que parece, Avogadro leu e refletiu sobre as ideias de Dalton e constatou que não poderia assumir que todos os gases possuem o mesmo número de partículas em um mesmo volume. Ele compreendeu que isso gerava inconsistências, como as da figura anterior. Foi então que, na tentativa de conciliar as ideias de Dalton com os experimentos de Gay-Lussac, Avogadro literalmente "inventou" o conceito de molécula diatômica, o que nas palavras dele foi chamado de "molécula constituinte". Avogadro diferencia "molécula elementar", "molécula constituinte" e "molécula integral". Aplicando esses conceitos para o caso da água, por exemplo, os átomos $\mathrm{H}$ e O são nomeados por ele de moléculas elementares, já as moléculas diatômicas de hidrogênio e oxigênio são chamadas por ele de moléculas constituintes, e a molécula de água, composta por dois hidrogênios e um oxigênio, ele chama de molécula integral. ${ }^{57}$

É curioso notar que quando assumimos as partículas dos gases simples como diatômicas, conforme as ideias de Avogadro - e não individuais, como pensava Dalton - isso nos permite pensar em três realizações muito interessantes e convenientes para a química. A primeira é assumir a existência do mesmo número de partículas por volume nos diferentes gases, tornando possível a famosa "hipótese de Avogadro":

"A hipótese [...] que parece [...] a única admissível é supor que o número de moléculas, [...] em qualquer gás, seja sempre o mesmo no mesmo volume ou sempre proporcional aos volumes." 58

A segunda, como consequência da primeira, permite determinar o número de partículas compondo a molécula da substância formada, dispensando o uso da regra de máxima simplicidade de Dalton. ${ }^{59}$ Já a terceira realização é que permite resolver as inconsistências na determinação dos pesos atômicos. Observaremos como isso se deu por meio de exemplos práticos.

\section{O caso do oxigênio na água}

Reinterpretando os dados do hidrogênio e do oxigênio na formação da água (representados na Figura 4), agora sob a ótica de Avogadro, ou seja, assumindo que todo gás tem o mesmo número de moléculas em um mesmo volume, que as moléculas dos gases simples são diatômicas, e também que dois volumes de hidrogênio reagem com um volume de oxigênio formando dois volumes de água (sob estado de vapor), temos o seguinte esquema (Figura 5):

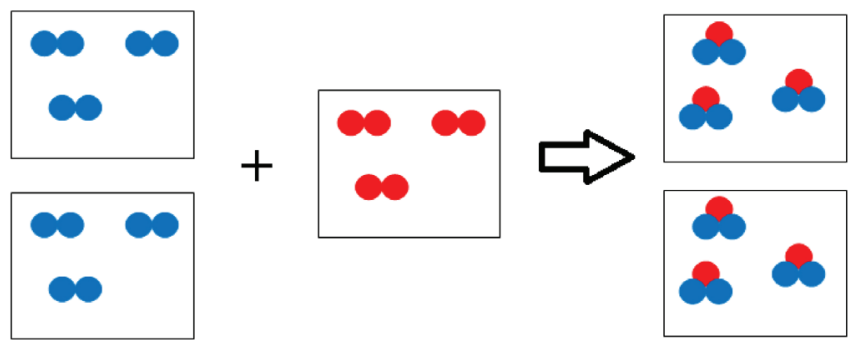

Figura 5. Reinterpretação da reação de hidrogênio com oxigênio formando água levando em conta o conceito de molécula constituinte de Avogadro ${ }^{60}$

Faz-se particularmente importante ressaltar que quando assumimos a existência de moléculas diatômicas para as substâncias simples, como o fez Avogadro, os átomos "param de se dividir", conforme Figura 4. Nesse sentido, é também curioso perceber que para podermos assumir que em todo gás existe o mesmo número de partículas em um mesmo volume, temos que, necessariamente, aceitar que não existem átomos individuais.

Então, como podemos ver, os conceitos de "molécula elementar", "molécula constituinte" e "molécula integral" são constructos teóricos ou invenções que viabilizam a "Hipótese de Avogadro". Essa última é especialmente importante, pois, quando assumimos que existe o mesmo número de partículas por volume, a constituição volumétrica das substâncias passa a orientar suas fórmulas moleculares, permitindo que se abra mão da regra de máxima simplicidade de Dalton. Ou seja, a água deixa de ser $\mathrm{HO}$, devido à regra $1 \mathrm{de}$ máxima simplicidade, e passa a ser $\mathrm{H}_{2} \mathrm{O}$, devido à sua constituição volumétrica. Em outras palavras, a água é $\mathrm{H}_{2} \mathrm{O}$ porque, na sua formação, quando olhamos a figura anterior, o número de átomos de hidrogênio (doze esferas azuis) é o dobro do número de átomos de oxigênio (seis esferas vermelhas). O leitor atento poderia nos questionar dizendo que nossa afirmação anterior apenas comprova que, na fórmula da água, a quantidade de hidrogênio é sempre o dobro da quantidade de oxigênio, o que nos leva a inferir que ela poderia ser $\mathrm{H}_{2} \mathrm{O}, \mathrm{H}_{4} \mathrm{O}_{2}, \mathrm{H}_{8} \mathrm{O}_{4}$ etc. No entanto, a redução de três volumes de gases iniciais (dois volumes de hidrogênio e um volume de oxigênio) para dois volumes de água também corrobora para inferirmos que a água seja $\mathrm{H}_{2} \mathrm{O}$. Visto que houve uma redução de 1/3 no volume, deve-se supor que o número de moléculas de água é 1/3 menor do que o número de moléculas iniciais, pois estamos assumindo que existe o mesmo número de moléculas por volume em qualquer gás. Como o número de moléculas iniciais para o exemplo proposto por nós é nove (seis de hidrogênio e três de oxigênio), então, com a redução de $1 / 3$, o número de moléculas formadas de água deve ser seis. Portanto, devemos "encaixar" os doze átomos de hidrogênio juntamente com os seis átomos de oxigênio nas seis moléculas de água, o que nos leva a propor a fórmula da água como sendo $\mathrm{H}_{2} \mathrm{O}$. Com isso, podemos concluir que os conceitos 
de "molécula elementar", "molécula constituinte" e "molécula integral", juntamente com a "Hipótese de Avogadro", são conceitos interdependentes. ${ }^{61}$

Sendo assim, de posse da nova fórmula molecular da água, agora com dois átomos de hidrogênio, temos que recalcular o peso relativo do átomo de oxigênio. Faremos isso usando os dados gravimétricos de Dalton.

Retomando, na constituição gravimétrica da água, a razão entre a quantidade de oxigênio e hidrogênio era 7, assim: $(87,4 \div 12,7=7)$. Ao reinterpretarmos isso para os átomos, a nova conta que deve ser feita é $(\mathrm{O} \div(2 \mathrm{x} 1)=7)$. Nesse caso, o novo peso relativo para o átomo de oxigênio passa a ser 14 (quatorze). ${ }^{62}$

\section{O caso do nitrogênio nos óxidos de nitrogênio e na amônia}

No caso dos óxidos de nitrogênio reinterpretados pela ótica de Avogadro, o gás nitroso passa a ser formado por um átomo de oxigênio e um de nitrogênio, por causa de sua composição volumétrica e não mais devido à regra 1 de máxima simplicidade.

Então, recalculando o peso do átomo de nitrogênio usando os dados aceitos por Dalton e tendo como pressuposto as ideias de Avogadro, temos que o nitrogênio pesa por volta de 12, pois a razão entre os átomos deve ser a mesma daquela obtida pela experiência $(46,6 \div 53,4=0,87)$. Sabe-se, a partir dos cálculos com a água, que o oxigênio pesa 14 , portanto o nitrogênio deve pesar 12,2 , pois $(\mathrm{N} \div 14=0,87)$.

No caso do óxido nitroso, a sua molécula é $\mathrm{N}_{2} \mathrm{O}$ devido à sua constituição volumétrica, ou seja, experimentalmente temos dois volumes de nitrogênio reagindo com um volume de oxigênio gerando óxido nitroso.

Recalculando o peso do átomo de nitrogênio, temos que o átomo de nitrogênio pesa 12,2 , pois, para o óxido nitroso $\mathrm{N}_{2} \mathrm{O}$, a razão entre os átomos $((2 \times \mathrm{N}) \div 14=1,74)$ deve ser a mesma daquela obtida pela experiência $(63,5 \div 36,5=1,74)$.

Já no ácido nítrico, a sua molécula é $\mathrm{NO}_{2}$, porque, experimentalmente, temos um volume de nitrogênio reagindo com dois volumes de oxigênio gerando dois volumes de ácido nítrico.

Estimando novamente o peso do átomo de nitrogênio, temos que ele pesa também por volta de 12 , pois, para o ácido nítrico $\mathrm{NO}_{2}$, a razão entre os átomos $(\mathrm{N} \div(2 \mathrm{x} 14)=0,42)$ deve ser a mesma daquela obtida pela experiência $(29,6 \div 70,4=0,42)$.

Já quanto à amônia, sua molécula não é mais $\mathrm{NH}$, conforme a regra de máxima simplicidade de Dalton. Ela passa a ser $\mathrm{NH}_{3}$ devido à sua constituição volumétrica, pois, por meio da experiência, sabemos que um volume de nitrogênio reage com três volumes de hidrogênio para formar dois volumes de amônia, assim (Figura 6):

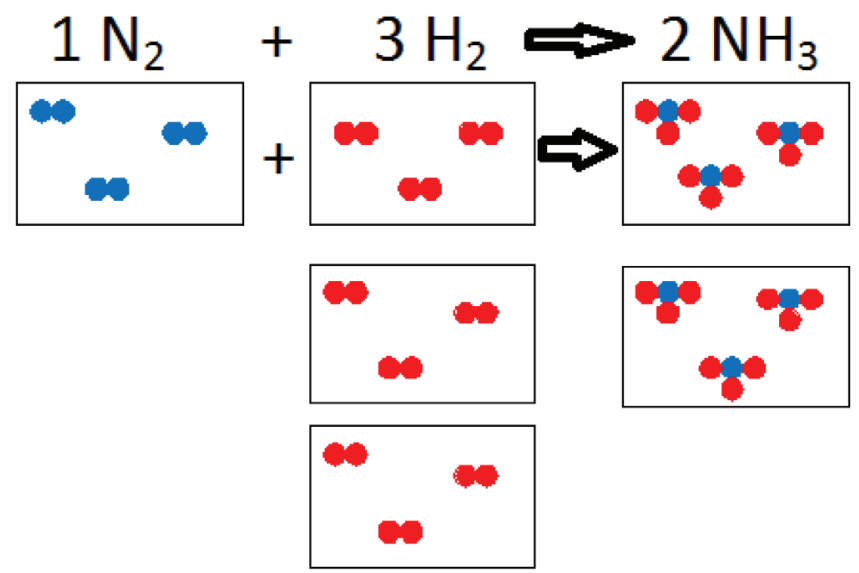

Figura 6. Composição volumétrica da amônia ${ }^{6.3}$
Recalculando o peso do átomo de nitrogênio proveniente da amônia, temos que o nitrogênio pesa por volta de 12 , pois, na amônia $\mathrm{NH}_{3}$, a razão entre os átomos $(\mathrm{N} \div(3 \mathrm{x} 1)=4,2)$ deve ser a mesma daquela obtida pela experiência $(121 \div 29=4,2)$.

É interessante relembrarmos nesse momento que o peso do átomo de nitrogênio gerado a partir da decomposição dos óxidos de nitrogênio - usando a regra de máxima simplicidade - era por volta de 6 , e quando sua origem era a amônia, o peso ficava por volta de 4 , uma diferença bastante significativa e difícil de explicar. Por outro lado, se reinterpretarmos as reações, agora usando as ideias de Avogadro, essas discrepâncias desaparecem e o nitrogênio passa a pesar por volta de $12 \mathrm{em}$ ambos os casos.

Obviamente, o leitor nesse momento deve estar questionando que os valores atualmente aceitos para o oxigênio e nitrogênio são um pouco diferentes dos descritos até aqui (14 para o oxigênio e 12 para o nitrogênio). Não podemos nos esquecer de que os instrumentos e as formas de medição sofreram transformações ao longo dos mais de 200 anos, ocasionando a retificação desses valores.

Apesar da correção dos pesos relativos, nosso modo de interpretar os gases simples como diatômicos persiste, a despeito dos muitos ataques que essa interpretação da matéria sofreu no século XIX. A seguir, mostraremos um pouco a respeito do processo de aceitação das ideias atômicas.

\section{A recepção das ideias atômicas no século XIX}

Inicialmente, as ideias de Dalton tiveram pouca aceitação por parte da maioria dos químicos influentes da época, pois o átomo não podia ser detectado experimentalmente de um modo direto. Nas palavras de Chagas:

"[o átomo era] uma hipótese útil, porém impossível de ser demonstrada. Esta atitude era alimentada pelo Positivismo de Augusto Comte, que considerava que a Ciência deveria tratar apenas com objetos e fenômenos perceptíveis pelos nossos sentidos, o que não acontece com os átomos e as moléculas, e estes, portanto, não podiam ser considerados como algo tratável pela Ciência." ${ }^{4}$

Assim como o átomo de Dalton teve pouca aceitação, as ideias de Avogadro não foram bem recebidas por confrontarem diretamente com os princípios da teoria dualista de um importante químico da época, Jöns Jacob Berzelius (1779-1848). Tal teoria só admitia a combinação entre átomos de cargas opostas, o que inviabilizava a concepção de moléculas diatômicas de Avogadro. ${ }^{65}$

Portanto, de modo geral, no século XIX preferiu-se a teoria dos equivalentes ao invés da teoria atômica para explicar a composição e a transformação da matéria. A expressão equivalente, introduzida no século XVIII por Henry Cavendish (1731-1810), foi retomada por Jeremias Benjamin Richter (1762-1807) e popularizada por William Hyde Wollaston (1766-1828). ${ }^{66}$

Oki nos aponta uma definição de equivalente químico:

"Na definição de equivalente químico encontram-se implícitas três importantes características: eram obtidos empiricamente de dados analíticos; o valor calculado dependia do tipo de composto analisado; existia possibilidade de um mesmo elemento apresentar mais de um valor de equivalente. Os pesos equivalentes de um dado elemento podiam ser numericamente iguais ao peso atômico ou a submúltiplos destes." ${ }^{67}$

Segundo Oki, entre os anos de 1808 e 1860, houve um intenso 
debate entre atomistas e equivalentistas nos principais países da Europa, sendo que:

"Este período é chamado por alguns historiadores da Química, [...] de 'intervalo equivalentista', caracterizado pelo uso do peso equivalente como suporte experimental na interpretação quantitativa das reações químicas e na menor valorização dos pesos atômicos." 68

Entretanto, com o passar do século XIX, as divergências entre atomistas e equivalentistas agravaram-se com o desenvolvimento da química orgânica. ${ }^{69} \mathrm{Na}$ busca de consenso sobre questões químicas da época, em 1860, foi realizado um congresso na cidade de Karlsruhe, na Alemanha. Nesse congresso, participaram 129 químicos de 12 países, e o italiano Stanislau Canizzaro (1826-1910) retomou as ideias de Avogadro para resolver a contradição Dalton x Gay-Lussac. ${ }^{70}$

Mesmo depois do congresso de 1860 e do trabalho de Canizzaro a favor da teoria atômica, ela ainda encontrava bastante resistência. Nomes importantes da época, como os de Friedrich Wilhelm Ostwald(1853-1932) e Marcellin Pierre Eugène Berthelot (18271907), criticavam duramente o atomismo. ${ }^{71}$

Entretanto, segundo Oki, no começo do século XX, Jean Baptiste Perrin (1870-1942), importante professor de Físico-Química da Universidade de Paris:

“[...]percebeu a importância de se encontrar evidências experimentais que fornecessem credibilidade à realidade atômica nos meios científicos. Ele assumiu como principal objetivo definir, usando procedimento empírico confiável, o valor de NA (constante de Avogadro) que aparecia em vários estudos cinéticos, mas que não possuía um valor consensualmente aceito." 72

O empreendimento de Perrin culminou com o lançamento do seu famoso livro Les atomes. Nele, Perrin determinou a constante de Avogadro por meio de 13 métodos totalmente diferentes. ${ }^{73}$ Seu empreendimento foi fundamental para a admissão das ideias atômicas, pois ele "[...] consegue encontrar um denominador comum para um grande número de fenômenos aparentemente desconectados." ${ }^{\text {. }}$ de Oki:

Vejamos a importância do trabalho de Jean Perrin nas palavras

"O trabalho de Perrin contribuiu para solucionar a interminável controvérsia sobre o atomismo que marcou o século XIX. [...]

As ideias de Perrin promoveram a aceitação do atomismo inclusive por Ostwald. Em 1909, ele reconheceu publicamente que os argumentos em favor da hipótese atômica não podiam mais ser ignorados, reconhecendo o mérito desta hipótese e a necessidade de que fosse restabelecida a confiança na representação atômica e corpuscular da matéria. Percebendo a importância do seu trabalho, Perrin se colocou no trecho a seguir, ratificando a importância da teoria atômica: 'Esse resultado confere à realidade molecular uma probabilidade próxima da certeza [...]. A teoria atômica triunfou'."75

Ainda de acordo com Oki, foi somente a partir de 1911, ano da primeira "Conferência Solvay", que os debates sobre o atomismo começaram a ser resolvidos para a grande maioria da comunidade científica. Após esse encontro, o átomo passou a ter uma grande aceitação como uma entidade científica, pois, graças à Perrin e outros, o diâmetro de um átomo e o número de partículas em um dado volume já podiam ser determinados. ${ }^{76}$

\section{CONSIDERAÇÕES FINAIS}

Como visto anteriormente, o professor costuma ter uma "visão aproblemática e ahistórica (portanto, dogmática e fechada)" do conhecimento científico. Como consequência, costuma apresentar aos seus alunos - de maneira dogmática e por meio de argumento de autoridade - os resultados cientificamente aceitos já prontos, ou seja, o de que a fórmula da água é $\mathrm{H}_{2} \mathrm{O}$, que o hidrogênio é $\mathrm{H}_{2}$ etc.

Por outro lado, a partir do episódio histórico selecionado, pudemos perceber a complexidade do processo de construção do conhecimento científico.

Em 1808, Dalton publicou as bases do seu atomismo. Percebemos que foi a partir dos experimentos de decomposição química, tendo como pressuposto a regra de máxima simplicidade, que Dalton estendeu a razão das massas encontradas nas balanças para os átomos. Apesar de interessante teoria, vimos que ela tinha muitos problemas de cálculos dos pesos atômicos, sendo o caso do nitrogênio aquele destacado neste trabalho.

Também pudemos notar que, com a publicação de 1809, GayLussac despertou um intenso debate a respeito da possibilidade de os gases terem o mesmo número de partículas por volume. Essa publicação provocou uma reação em Dalton, que, um ano depois, em 1810, provou que era impossível a existência do mesmo número de átomos individuais por volume nos diferentes gases.

Diante dessa impossibilidade, Avogadro, em 1811, "inventou" a molécula diatômica (molécula constituinte), o que possibilitou assumir que os gases tinham o mesmo número de moléculas por volume, viabilizando, assim, a sua famosa hipótese. Vimos que sua proposta resolveu muitos problemas de cálculo dos pesos atômicos na teoria de Dalton ${ }^{77}$ e que seu trabalho trouxe mais coerência e consistência à teoria atômica.

Por outro lado, na última parte do episódio histórico, pudemos notar a dificuldade de acolhimento de novas ideias pela comunidade acadêmica, tendo em vista que a teoria atômica demorou mais de cem anos para ser aceita amplamente pela comunidade científica.

Faz-se particularmente interessante ressaltar a importância de estudar episódios históricos para compreender aspectos da dinâmica da ciência. Como pudemos ver, o processo de elaboração e aceitação de teorias, modelos e conceitos é, muitas vezes, gradual. Esse processo é permeado de teorias alternativas, debates e controvérsias. Assim, acreditamos que seja de fundamental importância que o professor consiga ressaltar todos esses aspectos interessantes ao discutir esse episódio em sala de aula.

\section{AGRADECIMENTOS}

Ao Instituto Federal de Educação, Ciência e Tecnologia de São Paulo (IFSP) e à M. T. de B. Lobato, pelo apoio.

\section{REFERÊNCIAS}

1. El-Hani, C. N. Em Estudos de história e filosofia das ciências: Subsídios para aplicação no ensino; Marinho, J. R., ed.; Livraria da Física: São Paulo, 2006, cap. 1. p.3.

2. Matthews, M. R.; Caderno Catarinense de Ensino de Física 1995, 12, 165 .

3. Soares, M. A. C. P.; Dissertação de mestrado, Universidade Estadual de Maringá, Brasil, 2006, pp. 43-45.

4. Pérez, D. G.; Montoro, I. F.; Alís, J. C.; Cachapuz, A.; Praia, J.; Ciênc. Educ. (Bauru) 2001, 7, 125.

5. Ibid., 129-30

6. Ibid., 130-1.

7. Ibid., 131. 
8. Ibid., 131-2.

9. Ibid., 132-3.

10. Ibid., 133.

11. Ibid., 133.

12. Ibid., 133-4.

13. Ibid., 134.

14. Como visto anteriormente em nosso texto, os três problemas apontados por soares resumidamente são: "a fragmentação dos conhecimentos, a ausência de inteligibilidade e de sentido para o conhecimento e a perspectiva deformadora do saber científico [que] coadunam, impedindo que o aluno adquira uma visão clara e compreensível do que é a ciência." Soares, M. A. C. P.; Dissertação de mestrado, Universidade Estadual de Maringá, Brasil, 2006, pp. 43-45.

15. Martins, R. A. Em Estudos de história e filosofia das ciências: Subsídios para aplicação no ensino; Marinho, J. R., ed.; Livraria da Física: São Paulo, 2006, Introdução. p. XVII.

16. Ibid., XVII-XXII

17. Ibid., XXII.

18. Ibid., XXII-XXVI.

19. Ibid., XVII

20. Gagliardi, R.; Enseñanza de las Ciencias 1988, 6, 293.

21. São dez anos de experiência ministrando aulas de química para o ensino médio, mais quatro anos lecionando diferentes disciplinas para os cursos de licenciatura em química, bacharel em química industrial, e tecnologia em processos químicos. Nesses quatro anos, temos um bom tempo ministrando as disciplinas de química analítica qualitativa, quantitativa e instrumental, química geral além de disciplinas como história da ciência e da tecnologia, história e filosofia da ciência, e instrumentação para o ensino de química, o que nos proporcionou um longo período de prática e reflexão sobre a forma de usar história da ciência em sala de aula.

22. Estamos usando a expressão "estratégias pedagógicas" que está alinhado com Forato, T. C. M.; Pietrocola, M.; Martins, R. A.; Caderno Brasileiro de Ensino de Física 2011, 28, 27, pois não queremos entrar na desnecessária (para esse momento) discussão se História da ciência é "metodologia" ou é apenas um "recurso". Se é "método de ensino", ou é "mediadora para a aprendizagem de ciências" ou até mesmo "provedora de recursos que conduz à reflexão sobre o processo de construção do conhecimento científico". A esse respeito ver Saito, F.; História da Ciência e Ensino: Construindo Interfaces 2010, 1, 4.

23. É bom lembrar que sem o interesse e preparo adequado do Professor, esse tipo de proposta não é viável.

24. Forato, T. C. M.; Pietrocola, M.; Martins, R. A.; Caderno Brasileiro de Ensino de Física 2011, 28, pp. 28-54.

25. Aqui é importante lembrar que Dalton usava tanto os resultados de seus próprios experimentos, quanto os experimentos de seus contemporâneos, em sua argumentação.

26. Dalton, J.; A New System of Chemical Philosophy Part 1, $1^{\text {a }}$ ed., Londres, 1808, 213. Aqui é conveniente ressaltar que toda vez que nos referirmos ao "peso de um átomo" estamos nos referindo ao "peso relativo de um átomo" que é um termo criado por Dalton e que nada tem a ver com o tradicional conceito de peso e, muito menos, com o de massa.

27. Ibid., 211-20.

28. Ibid., 213-5.

29. Ibid., 215 .

30. Dalton, J.; A New System of Chemical Philosophy Part 2, 1ª ed., Londres, 1810, pp. 274-276.

31. Aqui Dalton se refere à primeira regra da regra de máxima simplicidade. Ela está no Dalton, J.; A New System of Chemical Philosophy Part 1, $1^{\text {a }}$ ed., Londres, 1808, 214.

32. Dalton, J.; A New System of Chemical Philosophy Part 2, $1^{\text {a }}$ ed., Londres, pp. 275-276.

33. Dalton, J.; A New System of Chemical Philosophy Part 2, $1^{\text {a }}$ ed.,
Londres, pp. 317-318. Essa tabela é uma construção nossa a partir de resultados descritos no trabalho de Dalton.

34. Observação - os nomes de antigamente eram bem diferentes dos de hoje.

35. Essa notação $\mathrm{N}_{2} \mathrm{O}$ e $\mathrm{NO}_{2}$ é uma notação moderna para facilitar o entendimento de nosso texto. É importante frisar que Dalton não usava esse tipo de notação.

36. Dalton, J.; A New System of Chemical Philosophy Part 2, $1^{\mathrm{a}}$ ed., Londres, p. 420, 427. Essa tabela é uma construção nossa a partir de resultados descritos no trabalho de Dalton.

37. Ver Dalton, J.; A New System of Chemical Philosophy Part 2, $1^{\text {a }}$ ed., Londres, pp. 427-436. Para saber mais sobre a escolha dos dados experimentais por Dalton ver Lobato, C. B.; Tese de Doutorado, Pontifícia Universidade Católica de São Paulo, Brasil, 2011, pp. 58-67.

38. Thackray, A. W.; ISIS 1966, 57, pp. 35-55.

39. Dalton, J.; A New System of Chemical Philosophy Part 2, 1 $1^{\text {a }}$ ed., Londres, p. 352.

40. Gay-Lussac, J. L.; Mémoires de lasociété d'arcueil 1809, 2, 218.

41. Gay-Lussac, J. L.; Mémoires de lasociété d'arcueil 1809, 2, 253.

42. Oki, M. C. M.; Quim. Nova 2009, 32, 1074.

43. Gay-Lussac, J. L.; Mémoires de lasociété d'arcueil 1809, 2, pp. 227-233 e também Gay-Lussac, J. L.; Mémoires de lasociété d'arcueil 1809, 2 , pp. 235-253.

44. Aqui é bom considerar que ao que parece Gay-Lussac não inferiu que todos os gases possuem o mesmo número de átomos em um mesmo volume a uma dada condição de temperatura e pressão. Essa foi uma conclusão tirada por Dalton caso a lei de Gay-Lussac fosse verdadeira. Dalton, J.; A New System of Chemical Philosophy Part 2, $1^{\text {a }}$ ed., Londres, p. 556.

45. Figura construída pelo autor

46. Dalton, J.; A New System of Chemical Philosophy Part 2, $1^{\text {a }}$ ed., Londres, p. 556.

47. Dalton, J.; A New System of Chemical Philosophy Part 1, $1^{\text {a }}$ ed., Londres, 1808, p. 188.

48. Ibid., 70-1.

49. Figura construída pelo autor.

50. Dalton, J.; A New System of Chemical Philosophy Part 2, $1^{\text {a }}$ ed., Londres, pp. 555-556.

51. Ibid., 558.

52. Ibid., 559.

53. Para ver a respeito da teoria das misturas gasosas e como os diferentes tamanhos dos átomos são a causa da mistura dos gases, ver Lobato, C. B.; Dissertação de Mestrado, Pontifícia Universidade Católica de São Paulo, Brasil, 2007, pp. 32-73.

54. Ver Lobato, C. B.; Tese de Doutorado, Pontifícia Universidade Católica de São Paulo, Brasil, 2011, pp. 78-110.

55. Figura construída pelo autor.

56. Neste artigo Avogadro cita os trabalhos e os nomes de Dalton e Gay Lussac muitas vezes, ver Avogadro, L. R. A. C.; Journal de Physique 1811, 73, pp. 58-62.

57. Avogadro, L. R. A. C.; Journal de Physique 1811, 73, pp. 58-62. Ver também Oki, M. da C. M.; Tese de Doutorado, Universidade Federal da Bahia, Brasil, 2006, p. 189.

58. Avogadro, L. R. A. C.; Journal de Physique 1811, 73, 58.

59. Nossa afirmação aqui está restrita apenas levando em consideração os compostos inorgânicos mais comuns. Não estamos levando em conta as confusões e interpretações equivocadas (aos olhos de hoje) sobre a composição das substâncias. conforme Perrin, J.; Atoms, $4^{\mathrm{a}}$ ed., D. Van Nostrand Co.: New York, 1916, p. 20.

60. Figura construída pelo autor.

61. Jean Perrin no início do século XX nos afirma que as conseqüências da hipótese de Avogadro têm sido amplamente confirmadas pela análise química para milhares de substâncias, sem nenhuma exceção. Ele também aponta que as supostas exceções são na verdade interpretações 
equivocadas sobre a composição das substâncias envolvidas. Nestas supostas exceções, os autores estão confundindo misturas de gases com gases simples, conforme Perrin, J.; Atoms, $4^{\mathrm{a}}$ ed., D. Van Nostrand Co. New York, 1916, p. 20.

62. É bom lembrar que Avogadro considerava outros valores de massa de hidrogênio e oxigênio na formação da água. Se formos levar em conta os valores aceitos por Avogadro, o átomo de oxigênio passa a pesar 15,074 conforme Avogadro, L. R. A. C.; Journal de Physique 1811, 73, 59.

63. Figura construída pelo autor. Aqui é interessante notar que houve uma redução do volume pela metade, ou seja, antes da reação tínhamos 4 volumes ( 1 de nitrogênio e 3 de hidrogênio) e depois da reação temos 2 volumes de amônia. Essa redução também corrobora para inferirmos que a amônia é $\mathrm{NH}_{3}$, pois, se houve uma redução de $50 \%$ do volume, deve-se supor que o número de moléculas de amônia é $50 \%$ menor que o número de moléculas iniciais. Como o número de moléculas iniciais para o exemplo proposto por nós é 12 ( 9 de hidrogênio e 3 de nitrogênio), então com a redução de 50\%, o número de moléculas de amônia tem que ser 6. Portanto devemos "encaixar" os 18 átomos de hidrogênio juntamente com os 6 átomos de nitrogênio nas 6 moléculas de amônia o que nos leva a propor a fórmula $\mathrm{NH}_{3}$.

64. Chagas, A. P.; Quim. Nova Esc. 2003, 17, 36.

65. Oki, M. C. M.; Quim. Nova 2009, 32, p. 1076-1077. Aqui é importante ressaltar que na molécula diatômica, os átomos que se combinavam tinham cargas iguais e portanto, segundo a teoria dualista de Berzelius não podiam se unir quimicamente.
66. Ibid., 1076-7.

67. Ibid., 1076 .

68. Ibid., 1076.

69. O desenvolvimento da química orgânica sugeria uma possível realidade atômica pois, era difícil explicar o fenômeno do isomerismo por exemplo, sem pensar no arranjo dos átomos.

70. Oki, M. C. M.; Quim. Nova 2009, 32, pp. 1076-1077.

71. Ibid., 1076-8.

72. Ibid., 1079-80.

73. Os métodos são: 1. Viscosidade de gases (teoria cinética, eq. Van der Waals); 2. Repartição vertical de grãos (emulsão diluída); 3. Movimento browniano: deslocamento; 4. Movimento browniano: rotações; 5 . Movimento browniano: difusão; 6. Opalescência crítica; 7. Azul do céu; 8. Espectro do corpo negro; 9. Carga de partículas microscópicas; 10. Radioatividade: Cargas projetada; 11. Radioatividade: Hélio produzido; 12. Radioatividade: Rádio decomposto; 13. Radioatividade: Energia irradiada. Conforme Perrin, J.; Atoms, $4^{\mathrm{a}}$ ed., D. Van Nostrand Co.: New York, 1916, p. 206, ver também Chagas, A. P.; Quim. Nova Esc. 2003, $17,37$.

74. Chagas, A. P.; Quim. Nova Esc. 2003, 17, 37.

75. Oki, M. C. M.; Quim. Nova 2009, 32, 1080.

76. Ibid., 1080.

77. Aqui é bom lembrar que com o avanço da química orgânica no século XIX, muitos outros problemas apareceram. 